\title{
Thermal Analysis of 2D FGM Beam Subjected to Thermal Loading Using Meshless Weighted Least-Square Method
}

\author{
H. M. Zhou (D), X. M. Zhang, and Z. Y. Wang \\ School of Mechanical and Power Engineering, Henan Polytechnic University, JiaoZuo, China \\ Correspondence should be addressed to H. M. Zhou; zhm_1979@163.com
}

Received 6 January 2019; Revised 18 March 2019; Accepted 10 April 2019; Published 30 April 2019

Academic Editor: Mohamed Shaat

Copyright (c) 2019 H. M. Zhou et al. This is an open access article distributed under the Creative Commons Attribution License, which permits unrestricted use, distribution, and reproduction in any medium, provided the original work is properly cited.

\begin{abstract}
The paper analyzed the thermal problem of the 2D FGM beam using meshless weighted least-square (MWLS) method. The MWLS as a meshless method is fully independent of mesh, and an approximate function was used to construct a series of linear equations to solve the unknown field variable, which avoided the troublesome task of numerical integration. The effectiveness and accuracy of the approach were illustrated by a clamped-clamped FGM beam which was subjected with interior heat source. The volume fraction of FGM beam was assumed to be given by a simple power law distribution. The effective material properties of the FGM beam were assumed to be temperature independent and calculated by Mori-Tanaka method. The results showed that a good agreement was achieved between the proposed meshless method and commercial COMSOL Multiphysics.
\end{abstract}

\section{Introduction}

FGMs can resist high temperatures and are proficient in reducing the thermal stress and have received more attention from the researchers [1]. Most of these researches on FGMs have been restricted to heat conduction analyses, thermal stress analyses, thermal buckling analyses, thermal vibration, and optimization problem. Various numerical techniques, such as the finite difference method (FDM) $[2,3]$, finite element method (FEM) [4-7], boundary element method (BEM) [8], or more recently developed meshless methods [9-23], have been developed for analyzing thermal related problems and other problems. Because of the complexity of the relevant governing equation, analytical solutions are usually difficult to obtain for those arbitrary geometry and complex boundary conditions, and the exact solutions are usually obtained based on classical plate theory, first-order shear deformation theory, high-order shear deformation theory, and so on $[24,25]$. Compared with FEM, FDM, and BEM, the meshless methods are associated with a class of numerical techniques that approximate a given differential equation or a set of differential equations using global interpolations on the discrete nodes or background mesh, exhibiting the advantages of avoiding mesh generation, simple data preparation, easy postprocessing, and so forth.
Liu and $\mathrm{Gu}$ [15] introduced meshless methods and their programming, such as the element-free Galerkin (EFG) method [12, 16], the hp-clouds method, the meshless local Petrov-Galerkin (MLPG) method [9, 10], meshless Galerkin method using radial basis functions [11, 14, 21], the least-square method [20], and meshless point interpolation method [19]. The main advantage of the MLPG method compared with regular Galerkin-based methods is that no background mesh is used to evaluate various integrals appearing in the local weak formulation of problem, but it requires a high-order quadrature rule to obtain converged results and thus needs much more computational effort in terms of CPU time than that for the FEM. Ching and Chen [9] proposed the thermoelastic analysis of a functionally graded composite considering temperature-dependent thermomechanical properties by the MLPG method. Andrew and Senthil [12] proposed a methodology for the two-dimensional simulation and optimization of material distribution of functionally graded materials for thermomechanical processes using a genetic algorithm. Katsikadelis [13] employed the meshless analog equation method to solve the $2 \mathrm{D}$ elastostatic problem for inhomogeneous anisotropic. A meshless algorithm of fundamental solution coupling with radial basis functions based on analog equation theory was proposed to simulate the static thermal stress distribution in 2D FGMs [14]. 
Mierzwiczak et al. [17] presented the singular boundary method for steady-state nonlinear heat conduction problems. Bhavani et al. [26] solved thermoelastic equilibrium equations for a functionally graded beam to obtain the axial stress distribution. Sohn and Kim [27] analyzed static and dynamic stabilities of FG panels which are subjected to thermal and aerodynamic loads. Hiroyuki [28] presented a two-dimensional (2D) higher-order deformation theory presented for the evaluation of displacements and stresses in functionally graded (FG) plates subjected to thermal and mechanical loading.

Zhou et al. presented steady-state [29] and transientstate [30] heat conduction analysis of heterogeneous material using the meshless weighted least-square method. In this paper the pure meshless method (MWLS) was then extended to solve problems of thermoelastic analysis for the FGM beam with interior heat source. The volume fractions of constituent materials composing the FGM beam are assumed to be given by a simple power law distribution. Material properties of the FGM are obtained by Mori-Tanaka method. The paper is divided as follows: firstly, we give problem description and MWLS analysis about the thermal problem. Then, in order to demonstrate the efficiency and accuracy of the proposed method, numerical implementation is given in the next section. The last section includes some conclusions.

\section{MWLS Analysis of the Thermal Problem}

The solution of MWLS analysis to the thermal problem is described in this section. The shape functions in MWLS analysis is a moving least-squares approximation scheme which is originally developed for the smooth interpolation of irregularly distributed data.

\subsection{The Moving Least-Square (MLS) Approximation Scheme.}

Construct the local approximate function $f^{h}(x)$ of an unknown field variable function $f(\boldsymbol{x})$ expressed as

$$
f(x) \approx f^{h}(\boldsymbol{x})=\boldsymbol{p}^{T}(\boldsymbol{x}) \boldsymbol{a}(\boldsymbol{x})
$$

where $\boldsymbol{p}^{T}(\boldsymbol{x})$ is the basis function and the quadratic basis $\boldsymbol{p}^{T}(\boldsymbol{x})=\left\{1, x, y, x^{2}, x y, y^{2}\right\}$ is used in this paper. In $2 \mathrm{D}$ space, the number of basis function $\mathrm{m}=6 ; \boldsymbol{a}(\boldsymbol{x})$ are unknown coefficients, which are solved by minimizing a weighted discrete residual given as

$$
\begin{aligned}
J J & =\sum_{I=1}^{N} \omega_{I}(\boldsymbol{x})\left[f^{h}\left(\boldsymbol{x}, \boldsymbol{x}_{I}\right)-f\left(\boldsymbol{x}_{I}\right)\right]^{2} \\
& =\sum_{I=1}^{N} \omega_{I}(\boldsymbol{x})\left[\boldsymbol{p}^{T}(\boldsymbol{x}) \boldsymbol{a}(\boldsymbol{x})-f\left(\boldsymbol{x}_{I}\right)\right]^{2}
\end{aligned}
$$

The minimum value of $J J$ may be achieved through differentiating with respect to $\boldsymbol{a}(\boldsymbol{x})$

$$
\begin{aligned}
\frac{\partial J J}{\partial a_{j}(\boldsymbol{x})} & =2 \sum_{I=1}^{N} \omega_{I}(\boldsymbol{x})\left[\sum_{i=1}^{m} p_{i}\left(\boldsymbol{x}_{I}\right) a_{i}(\boldsymbol{x})-f_{I}\right] p_{j}\left(\boldsymbol{x}_{I}\right) \\
& =0 \quad j=1,2, \ldots, m
\end{aligned}
$$

in which $\boldsymbol{x}_{I}$ are the positions of the $N$ nodes, $f_{I}$ refers to the nodal parameter of the field variable at node $I$, $f_{I}=f\left(\boldsymbol{x}_{I}\right) \cdot \omega_{I}(\boldsymbol{x})$ is the weighting function and usually a compactly supported function that is only nonzero in a small neighborhood called the "support domain" of node $\boldsymbol{x}_{I}$. The exponential function is used in this study.

$$
\omega(r)= \begin{cases}\frac{\left(\exp \left(-r^{2} \beta^{2}\right)-\exp \left(-\beta^{2}\right)\right)}{\left(1-\exp \left(-\beta^{2}\right)\right)} & r \leq 1 \\ 0 & r>1\end{cases}
$$

where $r=\left\|\boldsymbol{x}-\boldsymbol{x}_{I}\right\| / d_{m I}=\sqrt{\left(x-x_{I}\right)^{2}+\left(y-y_{I}\right)^{2}} / d_{m I}$ for circular support domain and $\beta$ is a constant. $d_{m I}$ denotes the radius of the circular support domain.

To obtain $\boldsymbol{a}(\boldsymbol{x})$, (3) can be rewritten in the matrix form

$$
\boldsymbol{A}(\boldsymbol{x}) \boldsymbol{a}(\boldsymbol{x})=\boldsymbol{B}(\boldsymbol{x}) \boldsymbol{f}
$$

where $\boldsymbol{A}(\boldsymbol{x})=\sum_{I=1}^{N} \omega_{I}(\boldsymbol{x}) \boldsymbol{p}\left(\boldsymbol{x}_{I}\right) \boldsymbol{p}^{T}\left(\boldsymbol{x}_{I}\right), \quad \boldsymbol{B}(\boldsymbol{x})=$ $\left[\begin{array}{llll}\omega_{1}(\boldsymbol{x}) p\left(\boldsymbol{x}_{1}\right) & \omega_{2}(\boldsymbol{x}) p\left(\boldsymbol{x}_{2}\right) & \ldots & \omega_{N}(\boldsymbol{x}) p\left(\boldsymbol{x}_{N}\right)\end{array}\right], \boldsymbol{f}=\left[f\left(\boldsymbol{x}_{1}\right)\right.$, $\left.f\left(\boldsymbol{x}_{2}\right), \ldots, f\left(\boldsymbol{x}_{N}\right)\right]^{T}$.

$d_{m I}$ is chosen to make $\boldsymbol{A}(\boldsymbol{x})$ be the nonsingular matrix everywhere in the whole domain; however, the circular support domain must have enough neighborhood nodes. Through finding out the $k k$ th nearest points of the evaluation point $\boldsymbol{x}$, the smallest support domain radius including these points can be obtained. The value of $k k$ is gained by comparing some numerical examples with their analytical solutions in Zhou et al. [29, 30].

Solving $\boldsymbol{a}(\boldsymbol{x})$ from (5), coefficients $\boldsymbol{a}(\boldsymbol{x})$ can be obtained

$$
\boldsymbol{a}(\boldsymbol{x})=A^{-1}(\boldsymbol{x}) \boldsymbol{B}(\boldsymbol{x}) \boldsymbol{f}
$$

Substituting (6) back into (1) and removing unknown $\boldsymbol{a}(\boldsymbol{x})$, we have

$$
f^{h}(\boldsymbol{x})=\boldsymbol{p}^{T}(\boldsymbol{x}) A^{-1}(\boldsymbol{x}) \boldsymbol{B}(\boldsymbol{x}) \boldsymbol{f}=\boldsymbol{S}(\boldsymbol{x}) \boldsymbol{f}
$$

Set $\boldsymbol{p}^{T}(\boldsymbol{x}) \boldsymbol{A}^{-1}(\boldsymbol{x}) \boldsymbol{B}(\boldsymbol{x})=\boldsymbol{S}(\boldsymbol{x})$, where $\boldsymbol{S}(\boldsymbol{x})$ is the shape function.

2.2. Heat Conduction Analysis of FGM Object. The steadystate heat conduction equation and the thermal boundary conditions of FGM objects are as follows, respectively,

$$
\begin{aligned}
& k(\boldsymbol{x}) \nabla^{2} T(\boldsymbol{x})+\nabla k(\boldsymbol{x}) \cdot \nabla T(\boldsymbol{x})+Q=0 \\
& \text { Dirichlet boundary: } T(\boldsymbol{x})=\bar{T} \quad x \in \Gamma_{1} \\
& \text { Neumann boundary: } \boldsymbol{n} \cdot k(\boldsymbol{x}) \nabla T(\boldsymbol{x})=\bar{q} \quad x \in \Gamma_{2} \\
& \text { Mixed boundary: } \boldsymbol{n} \cdot k(\boldsymbol{x}) \nabla T(\boldsymbol{x})=h\left(T_{\infty}-T(\boldsymbol{x})\right) \\
& \qquad x \in \Gamma_{3}
\end{aligned}
$$

where $T(\boldsymbol{x})$ is the temperature field on a fixed domain $\Omega$ surrounded by a closed boundary $\Gamma=\Gamma_{1}+\Gamma_{2}+\Gamma_{3}$. The variable $\boldsymbol{x}$ denotes the physical dimensions expressed in Cartesian coordinates, $\boldsymbol{x}:(x, y) . \boldsymbol{n}$ is the outward surface normal. The 
parameters $k, T_{\infty}, h$ and $Q$ are the thermal conductivity, ambient temperature, the heat transfer coefficient, and the heat resource, respectively.

Substituting the unknown temperature field variable $T(\boldsymbol{x})$ of (8) with the approximate function of (7), the residuals are minimized in a least-squares manner,

$$
\begin{aligned}
\delta & \prod=\int_{\Omega} \delta f_{J}\left[k \nabla^{2} S_{J}(x)+\nabla k \nabla S_{J}(x)\right] \\
\cdot & {\left[k \nabla^{2} S_{I}(x) f_{I}+\nabla k \nabla S_{I}(x) f_{I}+Q\right] d \Omega } \\
+ & \int_{\Gamma_{1}} \delta f_{J} S_{J}(x)\left[S_{I}(x) f_{I}-\bar{f}\right] d \Gamma+\int_{\Gamma_{2}} \delta f_{J} \boldsymbol{n} \\
\cdot & k \nabla S_{J}(x) \cdot\left(\boldsymbol{n} \cdot k \nabla S_{I}(x) f_{I}-\bar{q}\right) d \Gamma \\
+ & \int_{\Gamma_{3}} \delta f_{J}\left(\boldsymbol{n} \cdot k \nabla S_{J}(x)+h S_{J}(x)\right) \\
\cdot & {\left[\boldsymbol{n} \cdot k \nabla S_{I}(x) f_{I}-h\left(T_{\infty}-S_{I}(x) f_{I}\right)\right] d \Gamma }
\end{aligned}
$$

We use an alternative discrete equation to avoid integration and (10) can be rewritten as

$$
\begin{aligned}
\delta \prod= & \delta f_{J} \sum_{s=1}^{N}\left[k_{s} \nabla^{2} S_{J}\left(x_{s}\right)+\nabla k_{s} \nabla S_{J}\left(x_{s}\right)\right] \\
& \cdot\left[k_{s} \nabla^{2} S_{I}\left(x_{s}\right) f_{I}+\nabla k_{s} \nabla S_{I}\left(x_{s}\right) f_{I}+Q\right] \\
& +\delta f_{J} \sum_{s=1}^{N_{1}} S_{J}\left(x_{s}\right)\left[S_{I}\left(x_{s}\right) f_{I}-\bar{T}\right] \\
& +\delta f_{J} \sum_{s=1}^{N_{2}} \boldsymbol{n} \cdot k_{s} \nabla S_{J}\left(x_{s}\right) \cdot\left(\boldsymbol{n} \cdot k_{s} \nabla S_{I}\left(x_{s}\right) f_{I}-\bar{q}\right) \\
& +\delta f_{J} \sum_{s=1}^{N_{3}}\left[\boldsymbol{n} \cdot k_{s} \nabla S_{J}\left(x_{s}\right)+h S_{J}\left(x_{s}\right)\right] \\
& \cdot\left[\boldsymbol{n} \cdot k_{s} \nabla S_{I}(x) f_{I}-h\left(T_{\infty}-S_{I}\left(x_{s}\right) f_{I}\right)\right]
\end{aligned}
$$

The system equations of the MWLS method for solving steady-state heat conduction equations are written in a matrix form

$$
\begin{aligned}
& K T= P \\
& K=\sum_{s=1}^{N}\left[k_{s} \nabla^{2} S_{J}\left(x_{s}\right)+\nabla k_{s} \nabla S_{J}\left(x_{s}\right)\right] \\
& \cdot\left[k_{s} \nabla^{2} S_{I}\left(x_{s}\right)+\nabla k_{s} \nabla S_{I}\left(x_{s}\right)\right] \\
&+\sum_{s=1}^{N_{1}} S_{J}\left(x_{s}\right) S_{I}\left(x_{s}\right)+\sum_{s=1}^{N_{2}} \boldsymbol{n} \cdot k_{s} \nabla S_{J}\left(x_{s}\right) \boldsymbol{n} \\
& \cdot k_{s} \nabla S_{I}\left(x_{s}\right)+\sum_{s=1}^{N_{3}}\left[\boldsymbol{n} \cdot k_{s} \nabla S_{J}\left(x_{s}\right)+h S_{J}\left(x_{s}\right)\right] \\
& \cdot\left[\boldsymbol{n} \cdot k_{s} \nabla S_{I}(x)+h S_{I}(x)\right]
\end{aligned}
$$

$$
\begin{aligned}
P= & \left.-\sum_{s=1}^{N} k_{s} \nabla^{2} S_{J}\left(x_{s}\right)+\nabla k_{s} \nabla S_{J}\left(x_{s}\right)\right] Q \\
& +\sum_{s=1}^{N_{1}} S_{J}\left(x_{s}\right) \bar{T}+\sum_{s=1}^{N_{2}} \boldsymbol{n} \cdot k_{s} \nabla S_{J}\left(x_{s}\right) \bar{q} \\
& +\sum_{s=1}^{N_{3}}\left[\boldsymbol{n} \cdot k_{s} \nabla S_{J}\left(x_{s}\right)+h S_{J}\left(x_{s}\right)\right] h T_{\infty}
\end{aligned}
$$

where $I$ and $J$ refer to node indices, $N_{1}, N_{2}$, and $N_{3}$ is the number of interior nodes in the boundary $\Gamma_{1}, \Gamma_{2}$, and $\Gamma_{3}$, respectively.

2.3. Thermoelastic Analysis of FGM Object. Consider the 2D FGM anisotropic linear elastic body defined in the domain $\Omega$ bounded by $\Gamma$. The governing equation and boundary condition can be written in the following form disregarding the body forces

$$
\sigma_{i j, j}=0 \quad \text { in } \Omega
$$

stress boundary condition: $\sigma_{i j} n_{j}-\bar{t}_{i}=0$ on $\Gamma_{t}$

displacement boundary condition: $u_{i}=\bar{u}_{i}$ on $\Gamma_{u}$

in which $\sigma_{i j}$ is the components of the Cauchy stress tensor. A comma followed by index $j$ denotes the partial differentiation with respect to coordinate $x_{j}$ of a material point. $n_{j}$ is the unit outward normal to $\Gamma . u_{i}$ are the displacement components, and $\bar{u}_{i}$ are the prescribed displacements on $\Gamma_{u} . \bar{t}_{i}$ are the prescribed traction on $\Gamma_{t} . \Gamma_{u}$ and $\Gamma_{t}$ are the complementary parts of the boundary $\Gamma$. MWLS analysis requires a discretization of the domain $\Omega$; (15)-(16) becomes

$$
\begin{aligned}
& \sigma_{i j, j}\left(\boldsymbol{x}_{k}\right)=0 \quad \boldsymbol{x}_{k} \in \Omega, i, j=1,2 ; k=1,2, \ldots, N_{\Omega} \\
& \sigma_{i j}\left(\boldsymbol{x}_{k}\right) n_{j}=\bar{t}_{i}\left(\boldsymbol{x}_{k}\right) \\
& \boldsymbol{x}_{k} \in \Gamma_{t}, i, j=1,2 ; k=1,2, \ldots, N_{t} \\
& u_{i}\left(\boldsymbol{x}_{k}\right)=\bar{u}_{i}\left(\boldsymbol{x}_{k}\right) \\
& \boldsymbol{x}_{k} \in \Gamma_{u}, i=1,2 ; k=1,2, \ldots, N_{u}
\end{aligned}
$$

where $N_{\Omega}, N_{t}$, and $N_{u}$ is the number of interior nodes in the domain $\Omega$, in the boundary $\Gamma_{t}$ and $\Gamma_{u}$, respectively.

Substituting $\sigma_{i j}, u_{i}$ of (17) (19) with the approximate function of (7),

$$
\begin{aligned}
& \sum_{I=1}^{N} \boldsymbol{H}_{I}\left(x_{k}\right) \boldsymbol{f}_{I}=0 \quad x_{k} \in \Omega, k=1,2, \ldots, N_{\Omega} \\
& \sum_{I=1}^{N} \boldsymbol{Q}_{I}\left(x_{k}\right) \boldsymbol{f}_{I}=\overline{\boldsymbol{t}}_{k} \quad x_{k} \in \Gamma_{t}, k=1,2, \ldots, N_{t} \\
& \sum_{I=1}^{N} \boldsymbol{N}_{I}\left(x_{k}\right) \boldsymbol{f}_{I}=\overline{\boldsymbol{u}}_{k} \quad x_{k} \in \Gamma_{u}, k=1,2, \ldots, N_{u}
\end{aligned}
$$

where $\boldsymbol{H}, \mathbf{Q}$, and $\boldsymbol{N}$ denote shape function similar to $\boldsymbol{S}$ of (7) 


$$
\begin{aligned}
\boldsymbol{H}_{I}\left(x_{k}\right) & =\frac{E}{1-v^{2}}\left[\begin{array}{cc}
\frac{\partial^{2} N_{I}\left(x_{k}\right)}{\partial x^{2}}+\frac{1-v}{2} \frac{\partial^{2} N_{I}\left(x_{k}\right)}{\partial y^{2}} & \frac{1+v}{2} \frac{\partial^{2} N_{I}\left(x_{k}\right)}{\partial x \partial y} \\
\frac{1+v}{2} \frac{\partial^{2} N_{I}\left(x_{k}\right)}{\partial x \partial y} & \frac{\partial^{2} N_{I}\left(x_{k}\right)}{\partial y^{2}}+\frac{1-v}{2} \frac{\partial^{2} N_{I}\left(x_{k}\right)}{\partial x^{2}}
\end{array}\right] \\
\mathbf{Q}_{I}\left(x_{k}\right) & =\frac{E}{1-v^{2}}\left[\begin{array}{cc}
l \frac{\partial N_{I}\left(x_{k}\right)}{\partial x}+m \frac{1-v}{2} \frac{\partial N_{I}\left(x_{k}\right)}{\partial y} & l v \frac{\partial N_{I}\left(x_{k}\right)}{\partial y}+m \frac{1-v}{2} \frac{\partial N_{I}\left(x_{k}\right)}{\partial x} \\
m v \frac{N_{I}\left(x_{k}\right)}{\partial x}+l \frac{1-v}{2} \frac{\partial N_{I}\left(x_{k}\right)}{\partial y} & m \frac{\partial N_{I}\left(x_{k}\right)}{\partial y}+l \frac{1-v}{2} \frac{\partial N_{I}\left(x_{k}\right)}{\partial x}
\end{array}\right] \\
\boldsymbol{N}_{I} & =\left[\begin{array}{c}
\boldsymbol{N}_{I}\left(x_{k}\right) \\
0 \\
0 \\
\boldsymbol{N}_{I}\left(x_{k}\right)
\end{array}\right], \\
\boldsymbol{f}_{I} & =\left[\begin{array}{l}
f_{1 I} \\
f_{2 I}
\end{array}\right], \\
\overline{\boldsymbol{t}}_{k} & =\left[\begin{array}{l}
\bar{t}_{1}\left(x_{k}\right) \\
\bar{t}_{2}\left(x_{k}\right)
\end{array}\right] \\
\overline{\boldsymbol{u}}_{k} & =\left[\begin{array}{l}
\bar{u}_{1}\left(x_{k}\right) \\
\bar{u}_{2}\left(x_{k}\right)
\end{array}\right]
\end{aligned}
$$

where $l=\cos (N o, x), m=\cos (N o, y)$; No is the normal vector of any point.

Substituting the unknown field variable $\sigma_{i j}$ of (15) (16) into (1), the residuals are minimized in a least-squares manner,

$$
\begin{aligned}
\Pi= & \int_{\Omega} \sigma_{i j, j} \sigma_{i k, k} d \Omega+\int_{\Gamma u}\left(u_{i}-\bar{u}_{i}\right)\left(u_{i}-\bar{u}_{i}\right) d \Gamma u \\
& +\int_{\Gamma t}\left(\sigma_{i j} n_{j}-\bar{t}_{i}\right)\left(\sigma_{i j} n_{j}-\bar{t}_{i}\right) d \Gamma t
\end{aligned}
$$

Similar to (12) the system equations of the MWLS method for solving thermoelastic problem is written in the following matrix form

$$
K d=P
$$

where

$$
\begin{aligned}
\boldsymbol{K}= & \sum_{s=1}^{N} \boldsymbol{H}^{T}\left(x_{s}\right) \boldsymbol{H}\left(x_{s}\right)+\sum_{s=1}^{N_{u}} \boldsymbol{N}^{T}\left(x_{s}\right) \boldsymbol{N}\left(x_{s}\right) \\
& +\sum_{s=1}^{N_{t}} \mathbf{Q}^{T}\left(x_{s}\right) \mathbf{Q}\left(x_{s}\right) \\
\boldsymbol{P}= & \sum_{s=1}^{N_{u}} \boldsymbol{N}^{T}\left(x_{s}\right) \bar{u}_{s}+\sum_{s=1}^{N_{t}} \mathbf{Q}^{T}\left(x_{s}\right) \bar{t}_{s}
\end{aligned}
$$

where $\boldsymbol{H}, \boldsymbol{Q}$, and $\boldsymbol{N}$ are obtained by (23) (25) and $\boldsymbol{d}$ denotes the displacement of $\mathrm{x}, \mathrm{y},\left[u_{1}, u_{2}\right]$.

The thermal stresses is written in the matrix form

$$
\sigma=D \varepsilon-\beta T
$$

where $\boldsymbol{D}$ is the stiffness matrix for a linearly elastic, isotropic 2 -D solid. $\varepsilon$ is the infinitesimal strain vector.

$$
\begin{aligned}
\varepsilon & =\left[\frac{\partial u_{1}}{\partial x_{1}} \frac{\partial u_{2}}{\partial x_{2}} \frac{\partial u_{2}}{\partial x_{1}}+\frac{\partial u_{1}}{\partial x_{2}}\right]^{T}, \\
\boldsymbol{D} & =\frac{\bar{E}(x)}{1-\bar{v}(x)^{2}}\left[\begin{array}{ccc}
1 & \bar{v}(x) & 0 \\
\bar{v}(x) & 1 & 0 \\
0 & 0 & \frac{(1-\bar{v}(x))}{2}
\end{array}\right]
\end{aligned}
$$

in which $\bar{E}=E ; \bar{v}=v ; \beta=(\alpha E /(1-v))\left\{\begin{array}{l}1 \\ 1 \\ 0\end{array}\right\}$, for plane stress with $E, v$ and $\alpha$ denoting the Young's modulus, Poisson's ratio, and coefficient of thermal expansion, respectively, and $\bar{E}=E /\left(1-v^{2}\right) ; \bar{v}=v /(1-v) ; \beta=(\alpha E /(1-2 v))\left\{\begin{array}{l}1 \\ 1 \\ 0\end{array}\right\}$ for plane stain.

2.4. Material Properties. Two homogenization methods are often used to evaluate the effective material properties for FGMs. One is the rule of mixtures, and the other is the micromechanical model. The former is simply a linear rule of mixtures and the effective value can be determined by

$$
P=P_{1} V_{1}+P_{2} V_{2}
$$

where the volume fractions satisfy $V_{1}+V_{2}=1$, and $P$ may be elastic modulus $E$, bulk modulus $G$, Poisson's ratio $v$, coefficient of thermal expansion $a$, thermal conductivity $k$, and shear modulus $\mu$.

The most widely used micromechanical model is MoriTanaka model $[9,31]$. It is the modified rule of mixtures and 


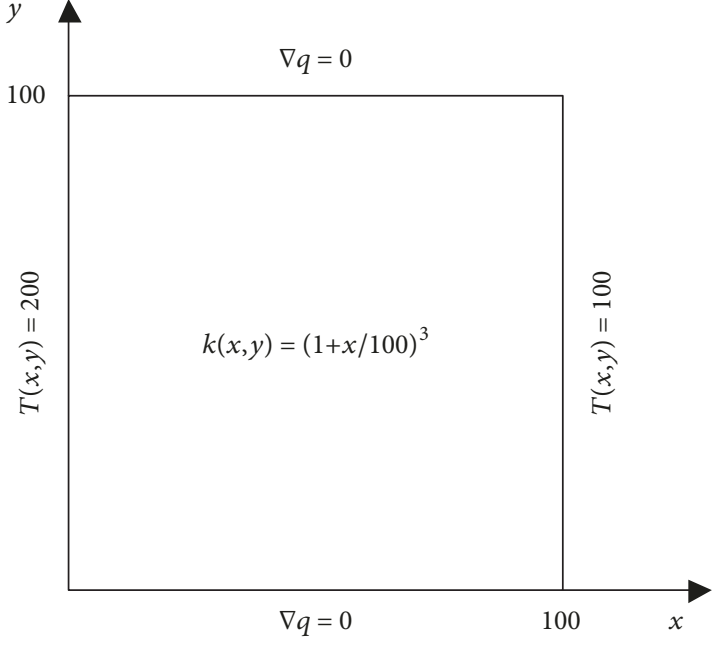

FIGURE 1: Geometry of square region and boundary conditions.

the effective material properties can be defined using the following relation,

$$
\begin{aligned}
& k=k_{1}+\frac{3 k_{1} V_{2}\left(k_{2}-k_{1}\right)}{3 k_{1}+V_{1}\left(k_{2}-k_{1}\right)} \\
& E=E_{1}+\frac{V_{2}\left(3 E_{1}+4 \mu_{1}\right)\left(E_{2}-E_{1}\right)}{3\left(1-V_{2}\right)\left(E_{2}-E_{1}\right)+3 E_{1}+4 \mu_{1}} \\
& \mu=\mu_{1}+\frac{V_{2}\left(\mu_{1}+f f_{1}\right)\left(\mu_{2}-\mu_{1}\right)}{\left(1-V_{2}\right)\left(\mu_{2}-\mu_{1}\right)+\mu_{1}+f f_{1}} \\
& \alpha=\alpha_{1}+\frac{E_{2}\left(E_{1}-E\right)\left(\alpha_{2}-\alpha_{1}\right)}{E\left(E_{1}-E_{2}\right)}
\end{aligned}
$$

where $G_{1}=E_{1} / 3\left(1-2 v_{1}\right) ; G_{2}=E_{2} / 3\left(1-2 v_{2}\right) ; \mu_{1}=E_{1} / 2(1+$ $\left.v_{1}\right) ; \mu_{2}=E_{2} / 2\left(1+v_{2}\right) ; f f_{1}=\mu_{1}\left(9 E_{1}+8 \mu_{1}\right) / 6\left(E_{1}+2 \mu_{1}\right)$.

\section{Numerical Results and Discussions}

In order to demonstrate the efficiency and accuracy of the presented method, firstly, we choose a isotropic square region (Case 1) with defined boundary conditions; through heat conduction analysis the results are compared with the analytical solutions and FDM. Then a clamped-clamped FGM beam (Case 2) which was subjected with interior heat source is analyzed using MWLS method.

3.1. Case 1. A $100 \times 100 \mathrm{~m}$ isotropic square region is shown in Figure 1. The top and bottom boundaries are insulated. The left and right boundaries are assigned a temperature of $200^{\circ} \mathrm{C}$ and $100^{\circ} \mathrm{C}$, respectively. The spatial variation of the thermal conductivity is taken to be cubic in the $\mathrm{x}$-direction as $k(x, y)=(1+x / 100)^{3}$.

An analytical solution is given as

$$
T(x, y)=\frac{800}{6}\left[\frac{1}{(1+x / 100)^{2}}+\frac{1}{2}\right]
$$

TABLE 1: Maximum of relative error.

\begin{tabular}{lcc}
\hline Cartesian grid & MWLS & FDM \\
\hline $10 \times 10$ & $0.15 \%$ & $0.35 \%$ \\
$20 \times 20$ & $0.05 \%$ & $0.077 \%$ \\
$30 \times 30$ & $0.024 \%$ & $0.033 \%$ \\
\hline
\end{tabular}

TABLE 2: Material property.

\begin{tabular}{lcc}
\hline Material property & $\mathrm{Al}$ & $\mathrm{SiC}$ \\
\hline $\mathrm{k}(\mathrm{W} / \mathrm{mK})$ & 233 & 65 \\
$\mathrm{E}(\mathrm{Pa})$ & $7 \mathrm{e} 10$ & $4.27 \mathrm{e} 11$ \\
$v$ & 0.3 & 0.17 \\
$\alpha(/ \mathrm{K})$ & $2.34 \mathrm{e}-5$ & $4.3 \mathrm{e}-6$ \\
\hline
\end{tabular}

The design region is discretized as $20 \times 20, \beta=4$ in (4), and the material properties are a linear rule of mixtures (Eq. (32)). The temperature field distribution is computed in Eq. (12)-(14) and shown in Figure 2. According to Wang et al. [32] the estimation rule is maximum of relative error $\%=\max \mid(f-$ $g) / f \mid \times 100 \%$, in which $f$ is the analytical solution and $g$ is numerical solution. Then, our MWLS method is compared with FDM in different resolutions. The results are shown in Table 1. Obviously our method has a high precision compared with the analytical solution in spite of any resolution.

3.2. Case 2. A clamped-clamped FGM beam is shown in Figure 3, length $\mathrm{L}=1 \mathrm{~m}$, width $\mathrm{D}=0.5 \mathrm{~m}$, and thickness $\mathrm{H}=0.1 \mathrm{~m}$; material property is shown in Table 2, interior heat source $\mathrm{Q}=5 \mathrm{e} 5 \mathrm{~W} / \mathrm{m} 3$; the spatial variation of the volume fraction of $\mathrm{Al}$ is taken to be a power law distribution in the $y$-direction as $V=(y / D)^{a}$.

The beam is assumed to be in a state of plane strain normal to the xy plane, and the design region is discretized as $31 \times 15$ and $61 \times 30$. The effective material properties are determined by the Mori-Tanaka model (Eq. (33) (36)). In order to verify the proposed computational method, we do some comparisons between the MWLS and the commercial COMSOL Multiphysics for a homogeneous material $(a=0)$, relevant results are shown in Figure 4 and listed in Table 3. The results obtained with the two methods are in good agreement in temperature field aspect; however, the $\mathrm{x}$-displacements and $\mathrm{y}$-displacement have a little difference in $31 \times 15$ grid and in $61 \times 30$ the results are in good agreement in Table 3 . From Figure 4 we also can know that our method and COMSOL Multiphysics have the same distribution trend. The maximum temperature $361.3 \mathrm{~K}$ is in the center $(0.5,0.25)$ of the beam.

For $\mathrm{a}=2$, we analyzed the heat conduction and thermoelastic problem using MWLS method. Temperature field distribution, $\mathrm{x}$-displacement, and $\mathrm{y}$-displacement are plotted in Figures 5, 6, and 7, respectively. Figure 5 indicates that the maximum temperature $425.6 \mathrm{~K}$ is higher than the homogeneous material of Figure 2(a), in the Cartesian coordinates $(0.5,0.179)$ of the beam. Figures 6 and 7 show that when subjected to temperature rise, the beam expands and the maximum y-displacement is located at the top middle of the beam. Then we do heat conduction analysis in different 


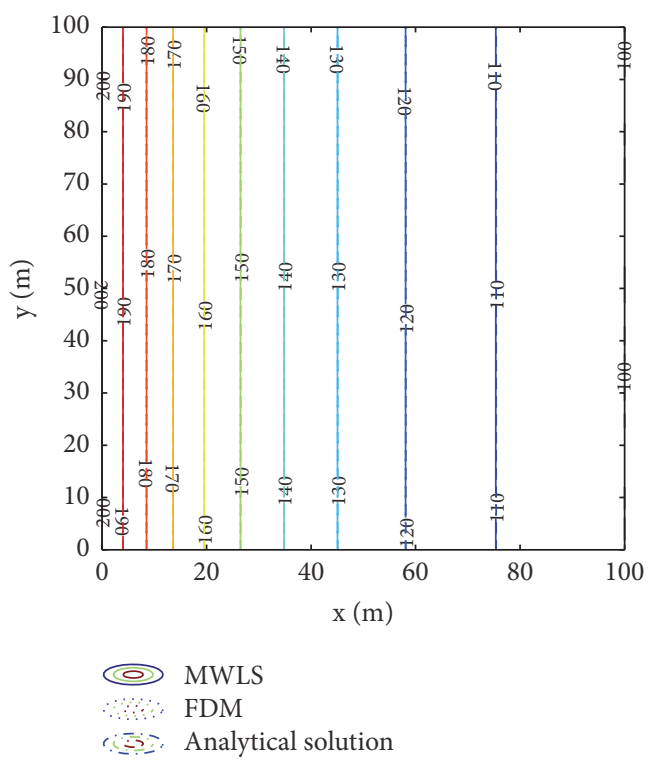

(a) 2D display

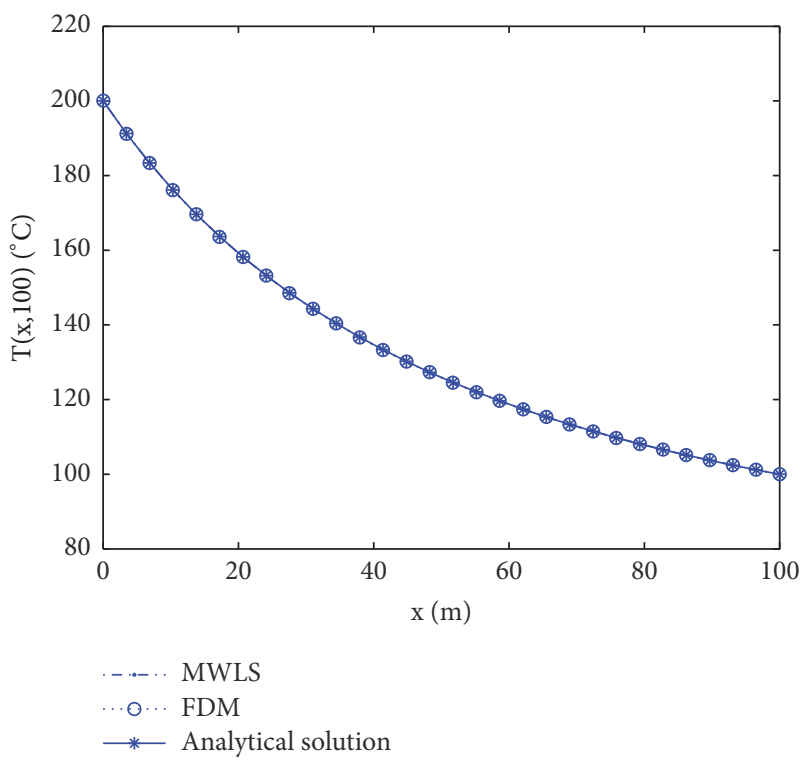

(b) Top boundary

FIgURE 2: Temperature field distribution $(20 \times 20)$.

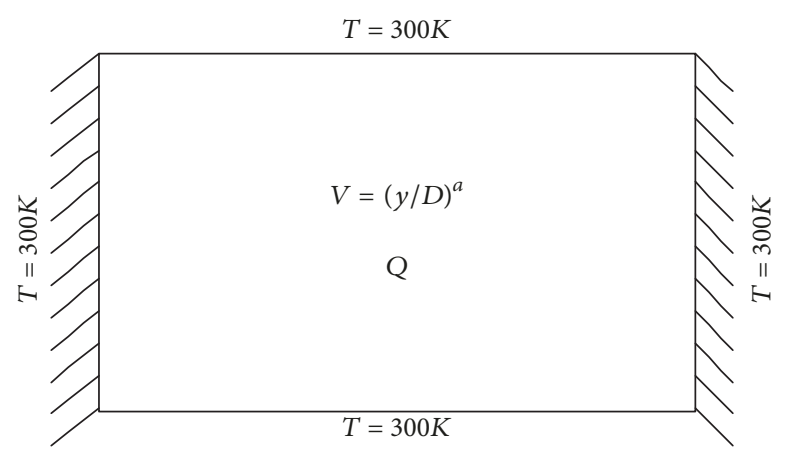

FIGURE 3: Initial condition.

material distribution in different heat source; the result is listed in Table 4. From Table 4, we can know that the maximum temperature of FGM model is higher than that of the fully metal model. Moreover, as the volume fraction index is increased, the maximum temperature increases. This is because for FGMs, when the volume fraction index is increased, the contained quantity of ceramic increases. Finally, to make a comparison, we do thermoelastic analysis and obtain thermal stresses in the neutral axis of the beam among $\mathrm{a}=0, \mathrm{a}=2$, and $\mathrm{a}=3$, as shown in Figure 8. In Figures $8(\mathrm{a})$ and 8 (c), the volume fraction of $\mathrm{Al}$ is gradually decreased from $\mathrm{a}=0$ to $\mathrm{a}=3$, the $\sigma \mathrm{x}$ and $\sigma \mathrm{y}$ stresses are in an upward trend. The maximum thermal stress always occurred in the vicinity of neutral axis of the beam from Figures 8(a), 8(c), and $8(\mathrm{~d})$. The results also agreed well with the presented elasticity solutions of [26].

\section{Conclusion}

In this paper, a novel thermoelastic analysis of FGM beam based on MWLS method was presented. We do thermoelastic and heat conduction analysis aimed at a clamped-clamped thick beam which is subjected with interior heat source. The FGM beam is assumed to be given by a simple power law distribution. Material properties of the FGM beam are obtained by Mori-Tanaka method. Through being compared with analytical solution and the commercial software of COMSOL Multiphysics, the effectiveness and accuracy are verified. We also listed the comparison of thermal stresses with the variation of power law index. The present method of analysis will be also useful in the design and optimization of FGM objects.

\section{Nomenclature}

$\boldsymbol{a}(\boldsymbol{x}): \quad$ Coefficient

$\boldsymbol{A}(\boldsymbol{x}), \boldsymbol{B}(\boldsymbol{x})$ : Matrices of computation

$d_{m I}: \quad$ Radius of the circular support

$f_{I}$ : The nodal parameter of the field

$I, J: \quad$ variable at node indices

k: $\quad$ Thermal conductivity 

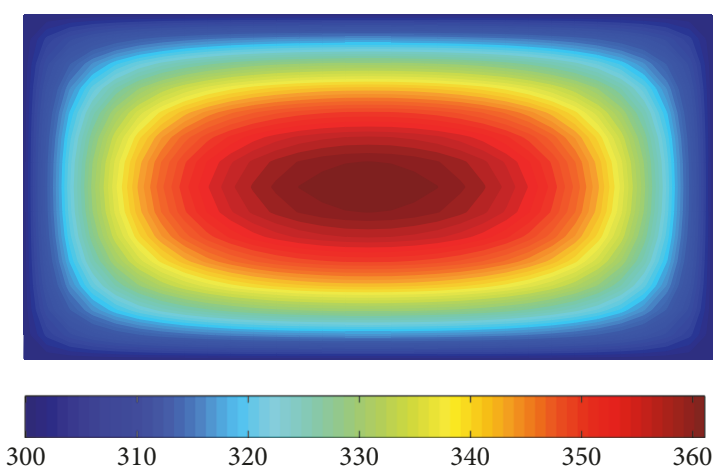

(a) Temperature field of our method

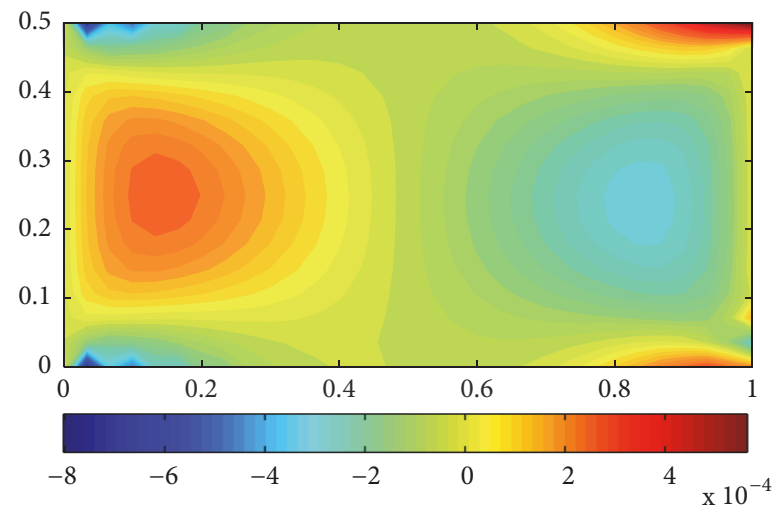

(c) x-displacement of our method

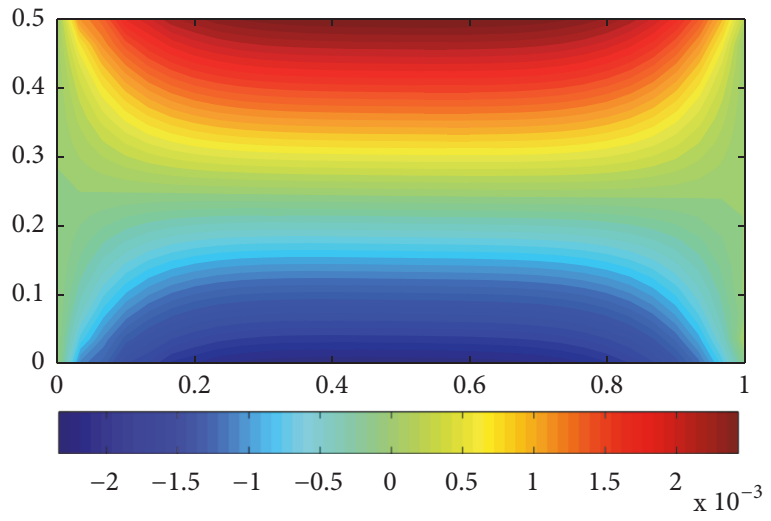

(e) y-displacement of our method

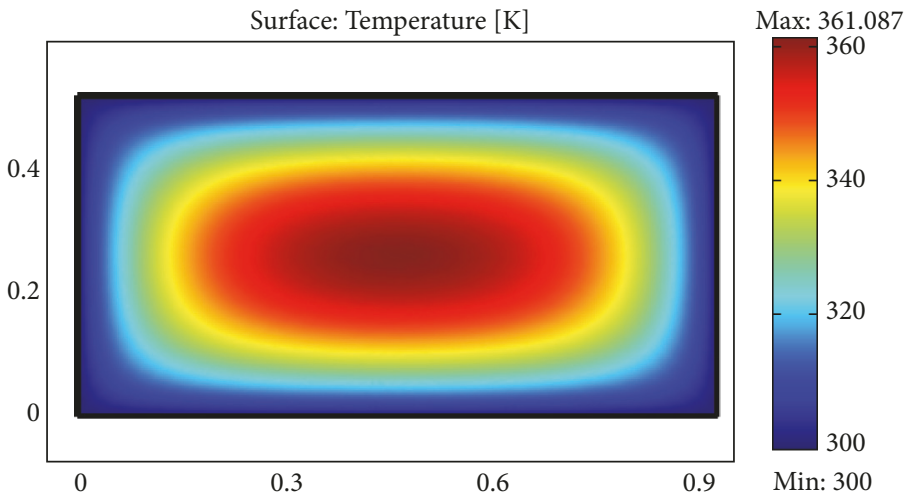

(b) Temperature field of COMSOL

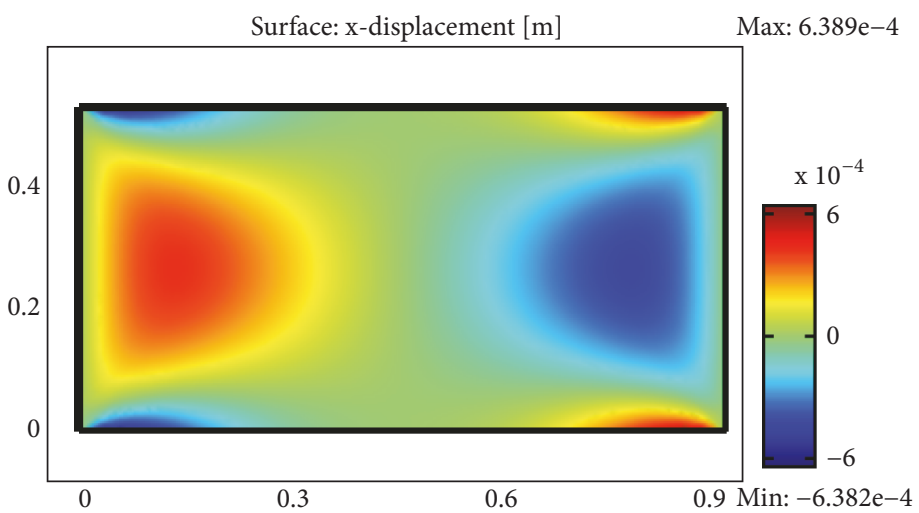

(d) x-displacement of COMSOL

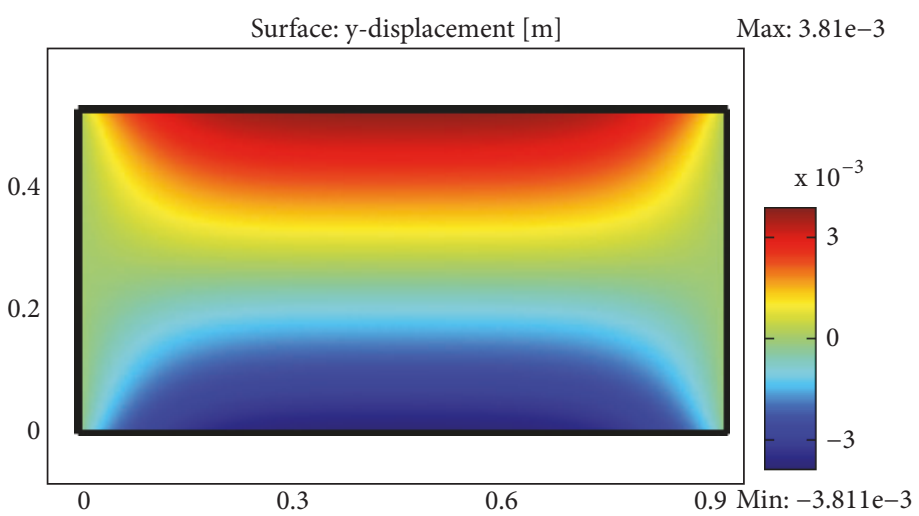

(f) $\mathrm{y}$-displacement of COMSOL

FIgURE 4: Comparison of our method with COMOSOL of $\mathrm{a}=0$.

TABLE 3: Comparison of MWLS method and COMSOL Multiphysics.

\begin{tabular}{|c|c|c|c|c|c|c|}
\hline \multirow{2}{*}{ method } & \multicolumn{2}{|c|}{ Temperature/K } & \multicolumn{2}{|c|}{$\mathrm{X}$ displacement $/ \mathrm{mm}$} & \multicolumn{2}{|c|}{ Y displacement $/ \mathrm{mm}$} \\
\hline & maximum & minimum & maximum & minimum & maximum & minimum \\
\hline MWLS (31×15) & 361.8 & 300 & .596 & -.873 & 2.95 & -2.8 \\
\hline MWLS $(61 \times 30)$ & 361.3 & 300 & .71 & -.72 & 3.88 & -3.84 \\
\hline COMSOL (948 triangle mesh) & 361.1 & 300 & .639 & -.639 & 3.81 & -3.81 \\
\hline
\end{tabular}


TABLE 4: Comparison of different material distribution in different heat source.

\begin{tabular}{|c|c|c|c|c|}
\hline \multirow{2}{*}{ MWLS $(31 \times 15)$} & \multicolumn{2}{|c|}{$\begin{array}{c}\text { Temperature } / \mathrm{K} \\
\mathrm{Q}=5 \mathrm{e} 5 \mathrm{~W} / \mathrm{m}^{3}\end{array}$} & \multicolumn{2}{|c|}{$\begin{array}{c}\text { Temperature } / \mathrm{K} \\
\mathrm{Q}=5 \mathrm{e} 6 \mathrm{~W} / \mathrm{m}^{3}\end{array}$} \\
\hline & maximum & minimum & maximum & minimum \\
\hline$a=0$ & 361.8 & 300 & 910.8 & 300 \\
\hline$a=2$ & 425.6 & 300 & 1558.2 & 300 \\
\hline$a=3$ & 436.1 & 300 & 1660.9 & 300 \\
\hline
\end{tabular}
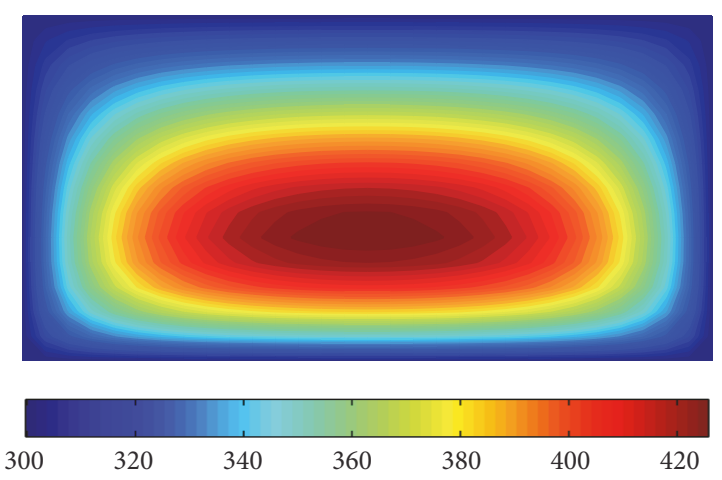

FIgURE 5: Distribution of temperature field.

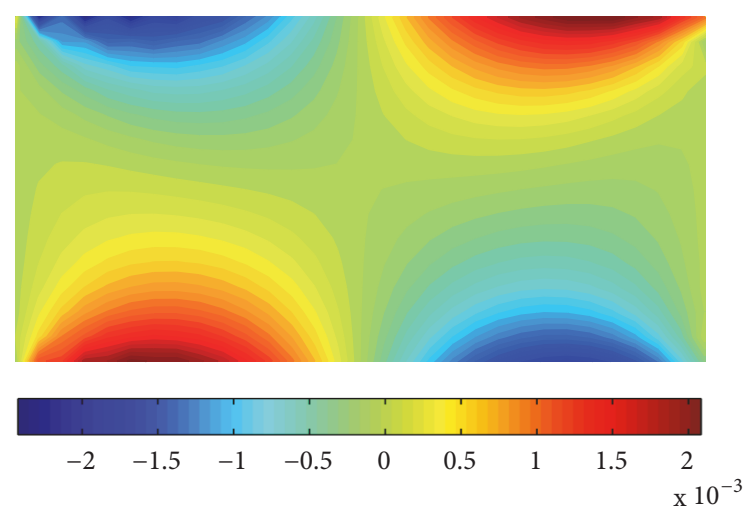

FIGURE 6: x-displacement/m.

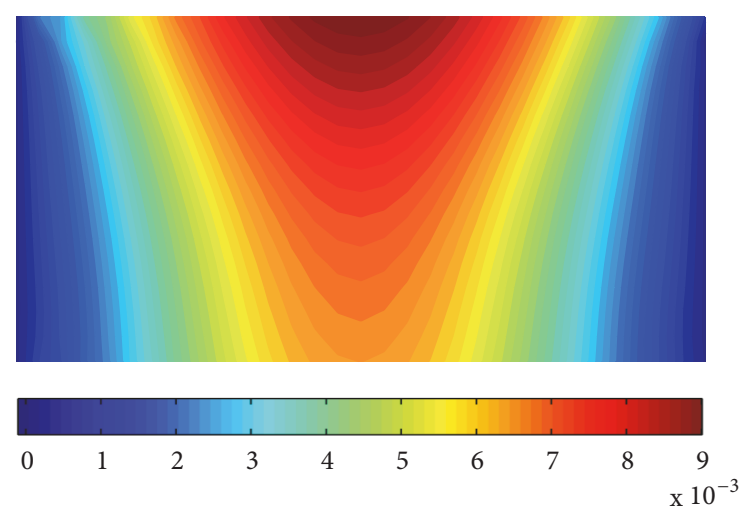

FIGURE 7: y-displacement/m.

\begin{tabular}{|c|c|}
\hline$k k:$ & Number of neighbor points \\
\hline$N:$ & Number of nodes \\
\hline$n:$ & Outward surface normal \\
\hline$S(x), N(x), H(x), Q(x):$ & Shape functions \\
\hline$N 1, N 2, N 3:$ & $\begin{array}{l}\text { Number of interior nodes in the } \\
\text { boundary } \Gamma_{1}, \Gamma_{2} \text { and } \Gamma_{3}\end{array}$ \\
\hline$p(x):$ & Basis function \\
\hline Q: & Heat source \\
\hline$\sigma_{i j}:$ & $\begin{array}{l}\text { Components of the Cauchy } \\
\text { stress tensor }\end{array}$ \\
\hline$\Gamma_{u}, \Gamma_{t}:$ & $\begin{array}{l}\text { Complementary parts of the } \\
\text { boundary } \Gamma\end{array}$ \\
\hline$D:$ & Stiffness matrix \\
\hline$E:$ & Young's modulus \\
\hline$\alpha:$ & Coefficient of thermal expansion \\
\hline$V:$ & Volume fraction \\
\hline$T:$ & Temperature \\
\hline$T_{\infty}:$ & Ambient temperature \\
\hline$h:$ & The heat transfer coefficient \\
\hline$f^{h}(\boldsymbol{x}):$ & $\begin{array}{l}\text { The moving least-square } \\
\text { approximation function }\end{array}$ \\
\hline$x_{I}:$ & The positions of the nodes \\
\hline$\Omega:$ & Fixed domain \\
\hline$\Gamma:$ & Closed boundary of $\Omega$ \\
\hline$\Gamma_{1}:$ & Dirichlet boundary \\
\hline$\Gamma_{2}:$ & Neumann boundary \\
\hline$\Gamma_{3}:$ & Mixed boundary \\
\hline$\omega_{I}(x):$ & Weight functions \\
\hline$q:$ & Normal heat flux \\
\hline $\bar{t}_{i}:$ & Given traction on $\Gamma_{t}$ \\
\hline$u_{i}:$ & Displacement components \\
\hline$d:$ & Displacement of $\mathrm{x}, \mathrm{y}$ \\
\hline$\varepsilon:$ & Infinitesimal strain vector \\
\hline$v:$ & Poisson's ratio \\
\hline$\mu:$ & Shear modulus \\
\hline G: & Bulk modulus. \\
\hline
\end{tabular}

\section{Data Availability}

The data used to support the findings of this study are included within the article.

\section{Conflicts of Interest}

The authors declare that they have no conflicts of interest. 


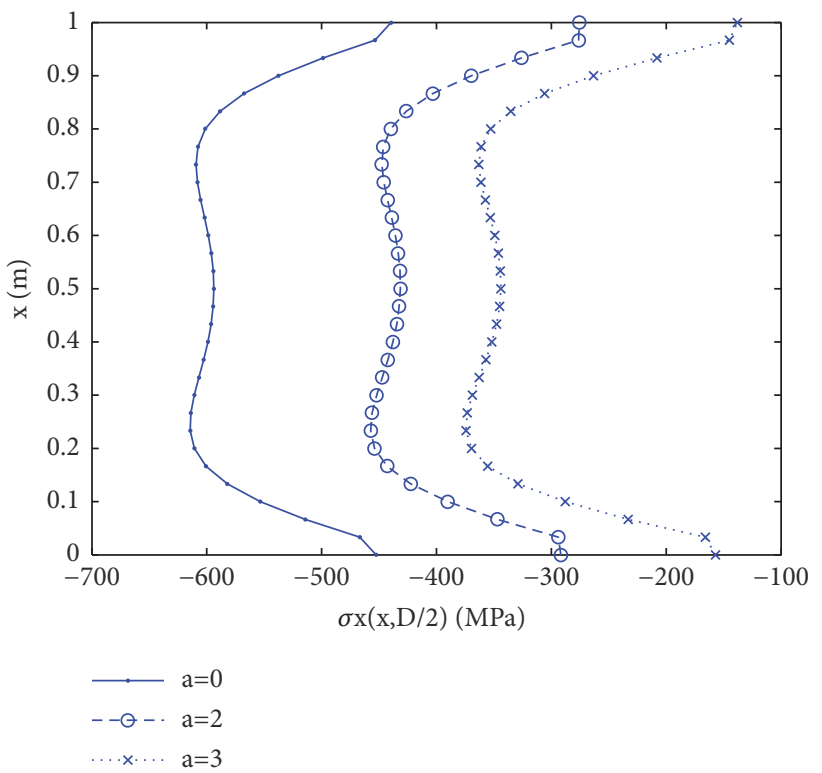

(a) $\sigma \mathrm{x}(\mathrm{x}, \mathrm{D} / 2)$

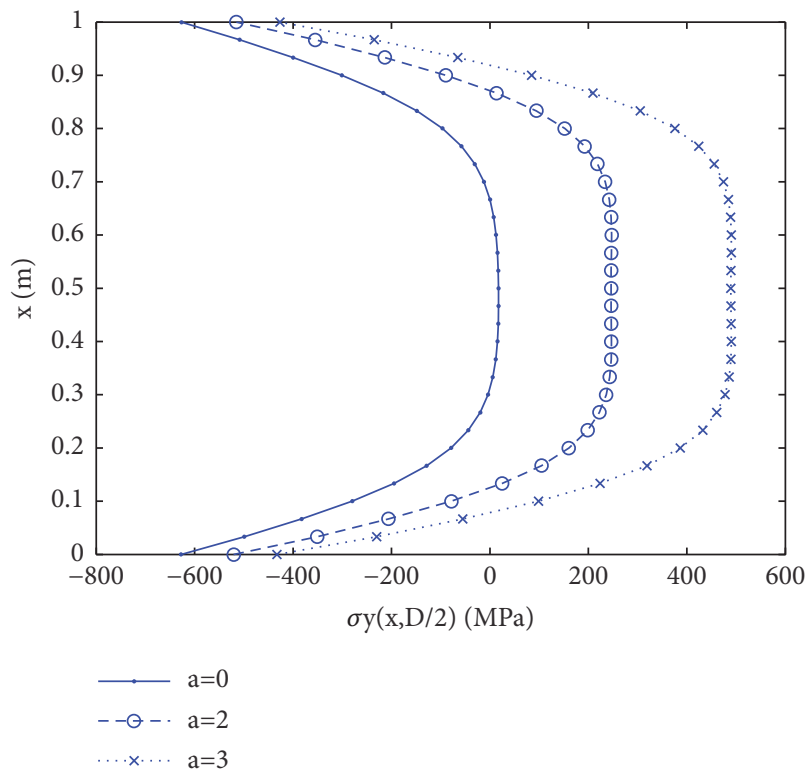

(c) $\sigma \mathrm{y}(\mathrm{x}, \mathrm{D} / 2)$

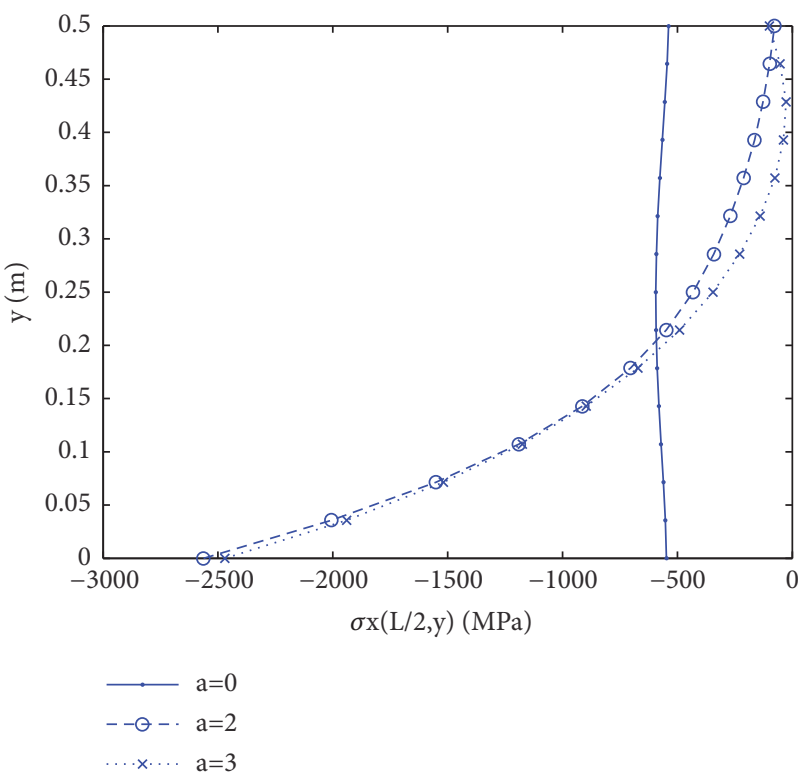

(b) $\sigma \mathrm{x}(\mathrm{L} / 2, \mathrm{y})$

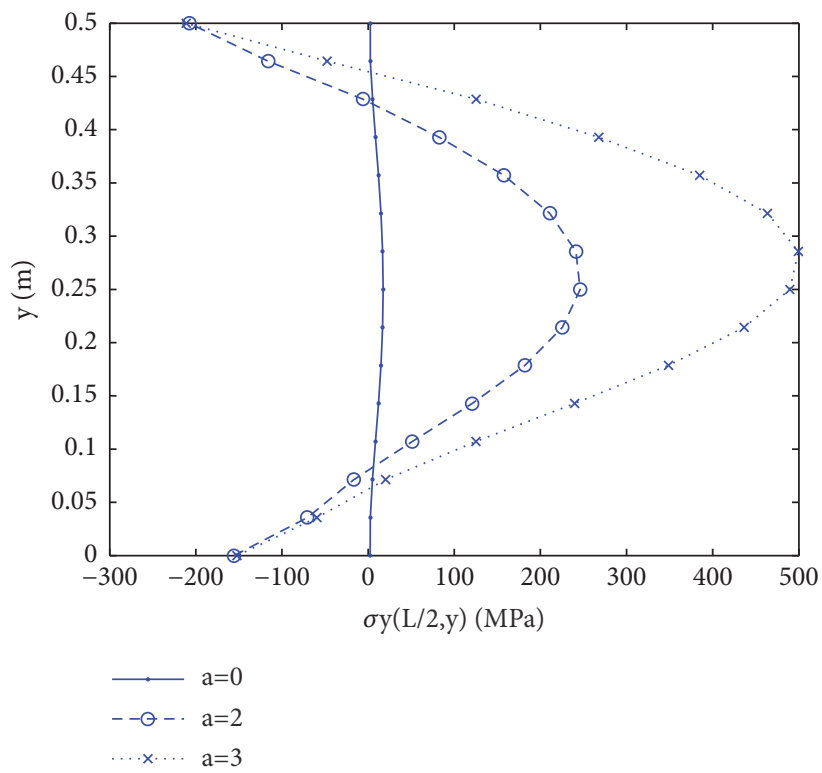

(d) $\sigma \mathrm{y}(\mathrm{L} / 2, \mathrm{y})$

FIGURE 8: Stress results comparison of thermoelastic analysis among $\mathrm{a}=0, \mathrm{a}=2$, and $\mathrm{a}=3$.

\section{Acknowledgments}

The work described in this paper was supported by a grant from the National Natural Science Foundation of China (Projects No. 51505131, U1504106) and Program for Innovative Research Team (No. T2017-3) of Henan Polytechnic University. The correlative members of the projects are hereby acknowledged.

\section{References}

[1] K. Swaminathan and D. Sangeetha, "Thermal analysis of FGM plates - A critical review of various modeling techniques and solution methods," Composite Structures, vol. 160, pp. 43-60, 2017.

[2] S. Turteltaub, "Optimal control and optimization of functionally graded materials for thermomechanical processes," International Journal of Solids and Structures, vol. 39, no. 12, pp. 31753197, 2002.

[3] J. R. Cho and D. Y. Ha, "Volume fraction optimization for minimizing thermal stress in $\mathrm{Ni}-\mathrm{Al} 2 \mathrm{O} 3$ functionally graded materials," Materials Science and Engineering: A Structural Materials: Properties, Microstructure and Processing, vol. 334, no. 1-2, pp. 147-155, 2002.

[4] K.-S. Na and J.-H. Kim, "Thermal postbuckling investigations of functionally graded plates using 3-D finite element method," 
Finite Elements in Analysis and Design, vol. 42, no. 8-9, pp. 749$756,2006$.

[5] X. Y. Kou and S. T. Tan, "A systematic approach for integrated computer-aided design and finite element analysis of functionally-graded-material objects," Materials and Corrosion, vol. 28, no. 10, pp. 2549-2565, 2007.

[6] M. Lezgy-Nazargah, "Fully coupled thermo-mechanical analysis of bi-directional FGM beams using NURBS isogeometric finite element approach," Aerospace Science and Technology, vol. 45, pp. 154-164, 2015.

[7] A. Najibi and R. Talebitooti, "Nonlinear transient thermoelastic analysis of a 2D-FGM thick hollow finite length cylinder," Composites Part B: Engineering, vol. 111, pp. 211-227, 2017.

[8] A. Sutradhar and G. H. Paulino, "The simple boundary element method for transient heat conduction in functionally graded materials," Computer Methods Applied Mechanics and Engineering, vol. 193, no. 42-44, pp. 4511-4539, 2004.

[9] H. K. Ching and J. K. Chen, "Thermal stress analysis of functionally graded composites with temperature-dependent material properties," Journal of Mechanics of Materials and Structures, vol. 2, no. 4, pp. 633-654, 2007.

[10] H. K. Ching and S. C. Yen, "Meshless local Petrov-Galerkin analysis for 2D functionally graded elastic solids under mechanical and thermal loads," Composites Part B: Engineering, vol. 36, no. 3, pp. 223-240, 2005.

[11] H. Wang and Q.-H. Qin, "Meshless approach for thermomechanical analysis of functionally graded materials," Engineering Analysis with Boundary Elements, vol. 32, no. 9, pp. 704-712, 2008.

[12] A. J. Goupee and S. S. Vel, "Two-dimensional optimization of material composition of functionally graded materials using meshless analyses and a genetic algorithm," Computer Methods Applied Mechanics and Engineering, vol. 195, no. 44-47, pp. 5926-5948, 2006.

[13] J. T. Katsikadelis, "The 2D elastostatic problem in inhomogeneous anisotropic bodies by the meshless analog equation method (MAEM)," Engineering Analysis with Boundary Elements, vol. 32, no. 12, pp. 997-1005, 2008.

[14] D. F. Gilhooley, J. R. Xiao, R. C. Batra, M. A. McCarthy, and J. W. Gillespie Jr., "Two-dimensional stress analysis of functionally graded solids using the MLPG method with radial basis functions," Computational Materials Science, vol. 41, no. 4, pp. 467-481, 2008.

[15] G. Liu and Y. T. RGu, An Introduction to Meshfree Methods And Their Programming, Springer, Berlin, Germany, 2005.

[16] S. Senthil, V. J. Goupee, and A. J. Goupee, "A methodology for the optimization of material composition of functionally graded materials," in Proceedings of the NSF DMII Grantees' Conference, Scottsdale, Ariz, USA, 2005.

[17] M. Mierzwiczak, W. Chen, and Z.-J. Fu, “The singular boundary method for steady-state nonlinear heat conduction problem with temperature-dependent thermal conductivity," International Journal of Heat and Mass Transfer, vol. 91, pp. 205-217, 2015.

[18] Z.-J. Fu, W. Chen, and Q.-H. Qin, "Boundary knot method for heat conduction in nonlinear functionally graded material," Engineering Analysis with Boundary Elements, vol. 35, no. 5, pp. 729-734, 2011.

[19] V. N. Van Do and C.-H. Lee, "Nonlinear analyses of FGM plates in bending by using a modified radial point interpolation meshfree method," Applied Mathematical Modelling: Simulation and
Computation for Engineering and Environmental Systems, vol. 57, pp. 1-20, 2018.

[20] L. Sator, V. Sladek, and J. Sladek, "Bending of FGM plates under thermal load: classical thermoelasticity analysis by a meshless method," Composites Part B: Engineering, vol. 146, pp. 176-188, 2018.

[21] J. Lin, S. Y. Reutskiy, and J. Lu, "A novel meshless method for fully nonlinear advection-diffusion-reaction problems to model transfer in anisotropic media," Applied Mathematics and Computation, vol. 339, pp. 459-476, 2018.

[22] J. Lin, C. Zhang, L. Sun, and J. Lu, "Simulation of seismic wave scattering by embedded cavities in an elastic half-plane using the novel singular boundary method," Advances in Applied Mathematics and Mechanics, vol. 10, no. 2, pp. 322-342, 2018.

[23] J. Lin, C. S. Chen, C.-S. Liu, and J. Lu, "Fast simulation of multi-dimensional wave problems by the sparse scheme of the method of fundamental solutions," Computers \& Mathematics with Applications, vol. 72, no. 3, pp. 555-567, 2016.

[24] S. S. Vel and R. C. Batra, "Exact solution for thermoelastic deformations of functionally graded thick rectangular plates," AIAA Journal, vol. 40, no. 7, pp. 1421-1433, 2002.

[25] A. Alibeigloo, "Exact solution for thermo-elastic response of functionally graded rectangular plates," Composite Structures, vol. 92, no. 1, pp. 113-121, 2010.

[26] B. V. Sankar and J. T. Tzeng, "Thermal stresses in functionally graded beams," AIAA Journal, vol. 40, no. 6, pp. 1228-1232, 2002.

[27] K.-J. Sohn and J.-H. Kim, "Structural stability of functionally graded panels subjected to aero-thermal loads," Composite Structures, vol. 82, no. 3, pp. 317-325, 2008.

[28] H. Matsunaga, "Stress analysis of functionally graded plates subjected to thermal and mechanical loadings," Composite Structures, vol. 87, no. 4, pp. 344-357, 2009.

[29] H. Zhou, Z. Liu, and B. Lu, "Heat conduction analysis of heterogeneous objects based on multi-color distance field," Materials \& Design, vol. 31, no. 7, pp. 3331-3338, 2010.

[30] H. M. Zhou, W. H. Zhou, G. Qin, Z. Y. Wang, and P. M. Ming, "Transient heat conduction analysis for distance-field-based irregular geometries using the meshless weighted least-square method," Numerical Heat Transfer, Part B: Fundamentals, vol. 71, no. 5, pp. 456-466, 2017.

[31] X. Peng, N. Hu, H. Zheng, and H. Fukunaga, "Evaluation of mechanical properties of particulate composites with a combined self-consistent and Mori-Tanaka approach," Mechanics of Materials, vol. 41, no. 12, pp. 1288-1297, 2009.

[32] H. Wang, Q. H. Qin, and Y. L. Kang, "A new meshless method for steady-state heat conduction problems in anisotropic and inhomogeneous media," Archive of Applied Mechanics, vol. 74, no. 8, pp. 563-579, 2005. 


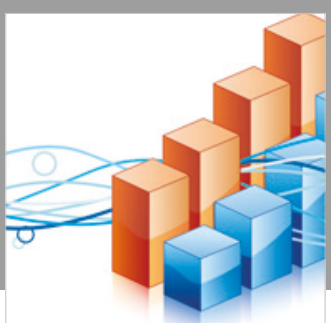

Advances in

Operations Research

\section{-n-m}
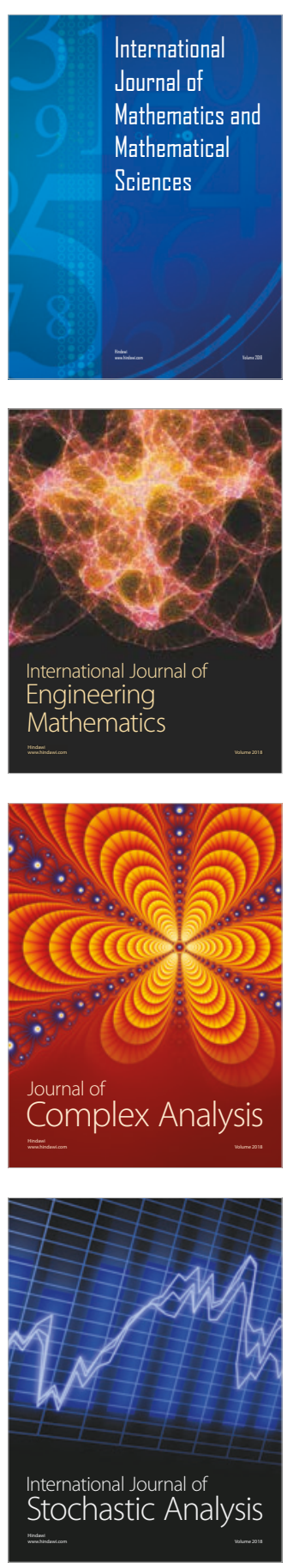
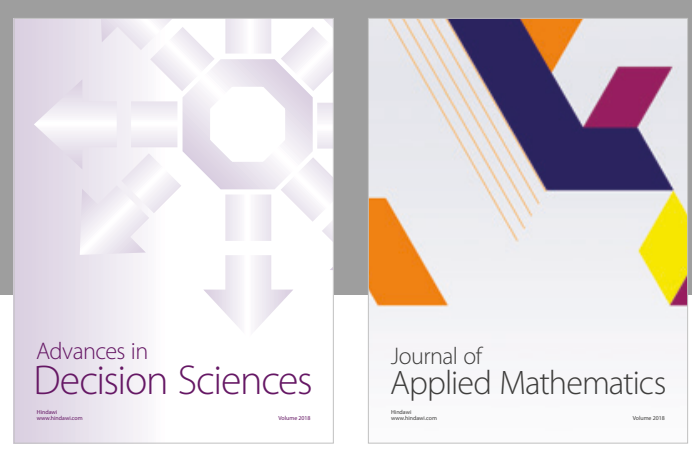

Journal of

Applied Mathematics
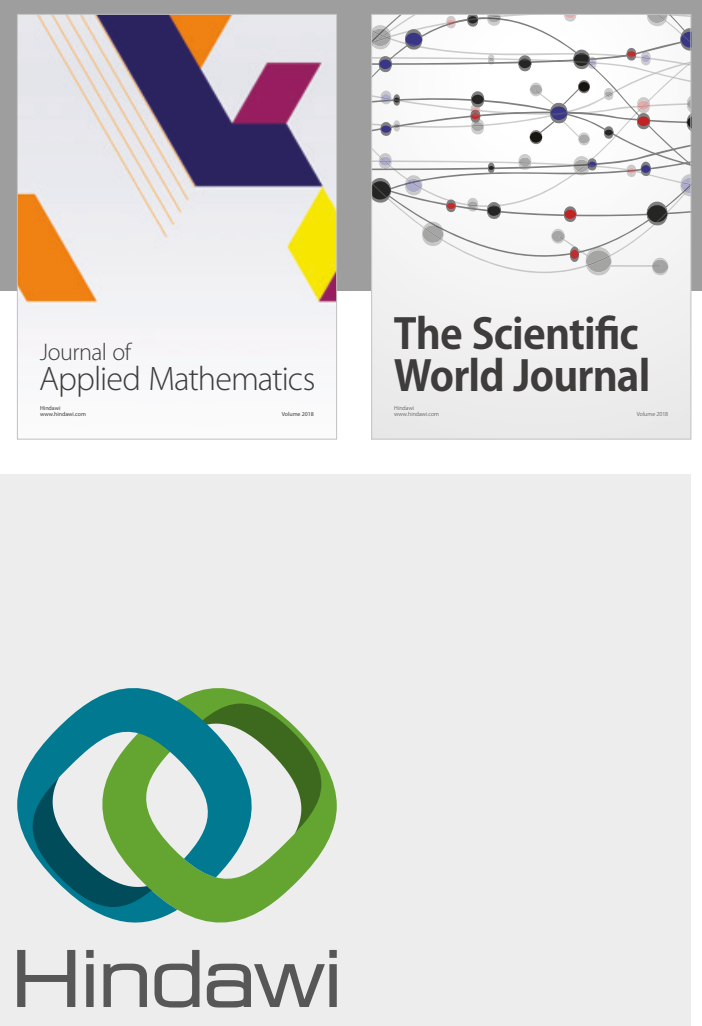

Submit your manuscripts at

www.hindawi.com

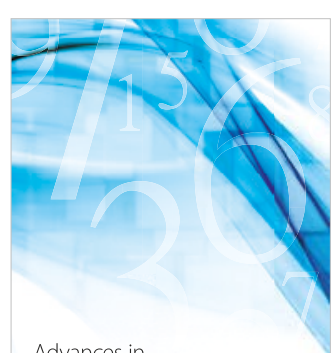

Advances in
Numerical Analysis
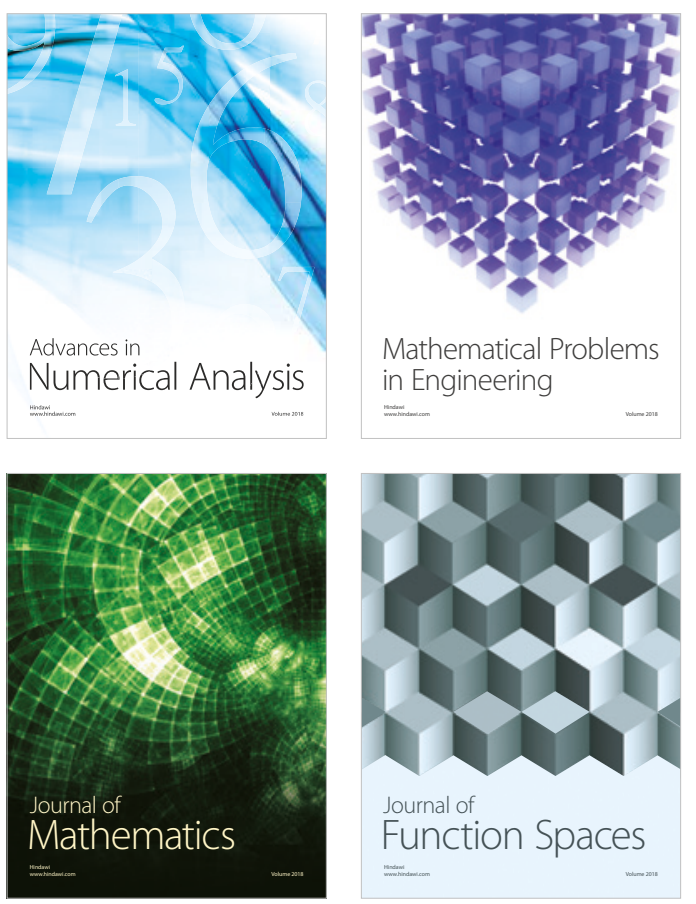

Mathematical Problems in Engineering

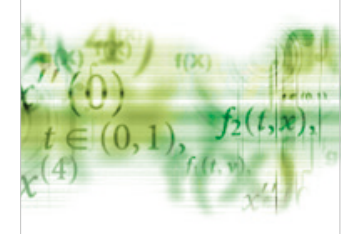

International Journal of

Differential Equations

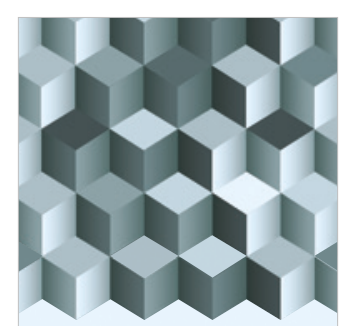

Journal of

Function Spaces

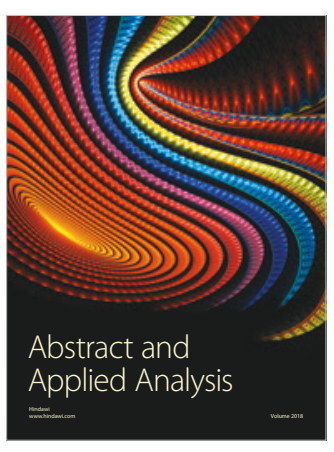

The Scientific

World Journal

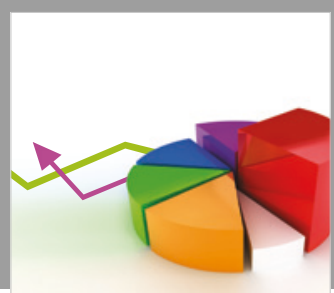

Journal of

Probability and Statistics
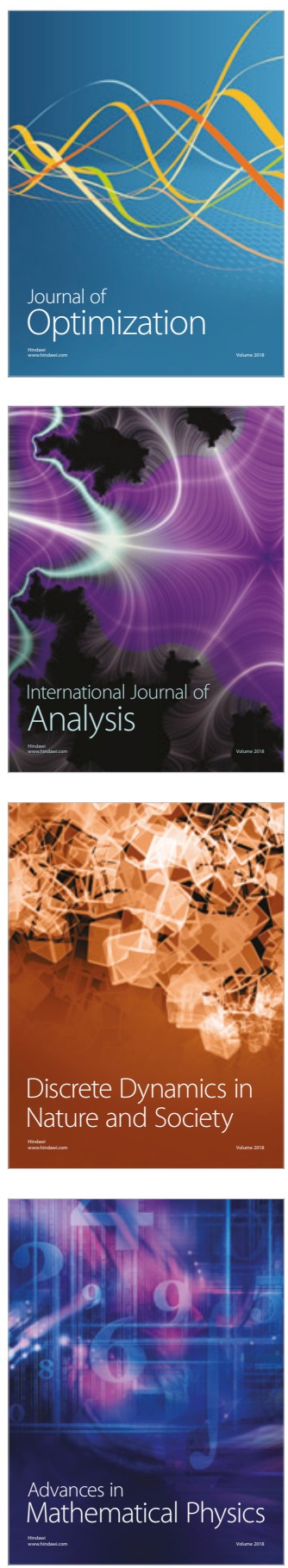